This item is the archived peer-reviewed author-version of:

Pre-adaptation or genetic shift after introduction in the invasive species ${ }^{* *}$ Impatiens glandulifera ${ }^{\star *}$ ?

\title{
Reference:
}

Elst Evelyne, Acharya Kamal P., Dar Pervaiz A., Reshi Zafar A., Tufto Jarle, Nijs Ivan, Graae Bente J..- Pre-adaptation or genetic shift after introduction in the invasive species ${ }^{\star *}$ Impatiens glandulifera ${ }^{\star *}$ ?

Acta oecologica - ISSN 1146-609X - 70(2016), p. 60-66

Full text (Publishers DOI): http://dx.doi.org/doi:10.1016/j.actao.2015.12.002 
1 Cite as: Elst EM, Acharya KP, Dar PA, Reshi ZA, Tufto J, Nijs I, Graae BJ (2016) Pre-adaptation or

2 genetic shift after introduction in the invasive species Impatiens glandulifera? Acta Oecologica 70: 60-66.

\section{Pre-adaptation or genetic shift after introduction in the invasive species Impatiens}

6 glandulifera?

7 Evelyne M. Elst ${ }^{1 *}$, Kamal P. Acharya ${ }^{2 *}$, Pervaiz A. Dar ${ }^{3}$, Zafar A. Reshi ${ }^{3}$, Jarle Tufto ${ }^{4}$, Ivan Nijs ${ }^{1}$, Bente J. Graae ${ }^{2}$ 8

$9{ }^{1}$ Centre of excellence PLECO (Plant and Vegetation Ecology), Department of Biology, University of Antwerp, 2610

10 Wilrijk, Belgium

11 2Department of Biology, Norwegian University of Science and Technology, 7491 Trondheim, Norway

$12{ }^{3}$ Biological Invasions Research Lab, Department of Botany, University of Kashmir, Srinagar-190006, Jammu and

13 Kashmir, India

$14{ }^{4}$ Department of Mathematical Sciences, Centre for Biodiversity Dynamics, Norwegian University of Science and

15 Technology, 7491 Trondheim, Norway

*These authors contributed equally to this work

Shared first authorship between EME and KPA. KPA and BJG designed the study. KPA, PAD and ZAR collected samples in the wild. KPA set up the experiment. EME did the measurements in the glasshouse and wrote the manuscript with help from KPA and IN. JT and EME did statistical analysis. All coauthors commented on the 22 manuscript.

24 All authors have approved the final article.

27 Corresponding author:

28 Evelyne Elst

29 Email: evelyne.elst@uantwerpen.be

30 Tel: +3232652272

31 Fax: +3232652271

32 
34 Invasive exotic plants often grow fast, reproduce rapidly and display considerable phenotypic plasticity in their

35 invasive range, which may be essential characteristics for successful invasion. However, it remains unclear whether

36 these characteristics are already present in native populations (pre-adaptation hypothesis) or evolve after

37 introduction (genetic shift hypothesis).

38 To test these hypotheses we compared means and phenotypic plasticity of vegetative and reproductive traits between

39 populations of Impatiens glandulifera collected from either the invasive (Norway) or native range (India). Seeds

40 were sown and the resulting plants were exposed to different experimental environments in a glasshouse. We also

41 tested whether trait means and reaction norms harbored genetic variation, as this may promote fitness in the novel

42 environment.

43 We did not find evidence that invasive populations of I. glandulifera grew more vigorously or produced more seeds

44 than native populations. Phenotypic plasticity did not differ between the native and invasive range, except for the

45 number of nodes which was more plastic in the invasive range. Genetic variation in the slope of reaction norms was

46 absent, suggesting that the lack of change in phenotypic plasticity between native and invasive populations resulted

47 from low genetic variation in phenotypic plasticity initially harbored by this species. Post-introduction evolution of

48 traits thus probably did not boost the invasiveness of I. glandulifera. Instead, the species seems to be pre-adapted for

49 invasion.

50 We suggest that differences in habitat between the native and invasive range, more specifically the higher nutrient

51 availability observed in the new environment, are the main factor driving the invasion of this species. Indeed, plants

52 in the more nutrient-rich invasive range had greater seed mass, likely conferring a competitive advantage, while seed

53 mass also responded strongly to nutrients in the glasshouse. Interactions between habitat productivity and herbivore

54 defense may explain the lack of more vigorous growth in the new range.

56 Keywords: biological invasion; genetic shift hypothesis; Impatiens glandulifera; pre-adaptation; phenotypic

57 plasticity

58 
60 Biological invasion is a global phenomenon causing ecological, economic and social disruption (Davis et al. 2000).

61 Alien invasive species often outcompete native species, affecting biodiversity and altering the structure and function

62 of invaded ecosystems (Vitousek et al. 1996; Bossdorf et al. 2005). Identifying traits or mechanisms responsible for

63 species invasiveness is crucial to predict the fate, spread and impact of invasive species and to take sound

64 management decisions.

65 Numerous studies have identified traits associated with invasiveness in plants (e.g. Theoharides and Dukes 2007;

66 Hayes and Barry 2008; Whitney and Gabler 2008; van Kleunen et al. 2010). These include - among others -

67 vigorous growth, abundant reproduction and high phenotypic plasticity (i.e. the ability of an organism to change its

68 phenotype in response to different environments) of morphological and physiological traits (Richards et al. 2006;

69 Whitney and Gabler 2008; van Kleunen et al. 2010; Godoy et al. 2011). However, where in the invasion pathway

70 such traits originate is still unclear. According to the pre-adaptation hypothesis, species become invasive if

71 characteristics that promote invasiveness are already present in the native range (Lee and Gelembiuk 2008; Mason et

72 al. 2008; Hejda et al. 2009; Schlaepfer et al. 2010). Alternatively, the genetic-shift hypothesis states that invasive

73 phenotypes arise from rapid evolution after introduction (DeWalt et al. 2004; Caño et al. 2008; Lande 2009; Qing et

74 al. 2011; Colautti and Barrett 2013). In the latter case, the small size of an introduced population typically first

75 causes reduced genetic diversity (founder effect) which can be accompanied by inbreeding (Kaufmann and Smouse

76 2001; DeWalt et al. 2004; Maron et al. 2004; Bossdorf et al. 2005; Caño et al. 2008; Prentis et al. 2008; Qing et al.

77 2011). Post-introduction natural selection by - and local adaptation to - the abiotic and biotic conditions in the

78 invasive range will further change the species genotype, giving rise to a novel micro-evolutional trajectory

79 (Kaufmann and Smouse 2001; Blair and Wolfe 2004; DeWalt et al. 2004; Maron et al. 2004; Bossdrof et al. 2005;

80 Caño et al. 2008; Feng et al. 2008; Barney et al. 2009; Qing et al. 2011; Li et al. 2015).

81 To distinguish whether a species is pre-adapted to invasion or has evolved after introduction, its traits need to be

82 compared between native and invasive populations along a common environmental gradient (DeWalt et al. 2004;

83 Maron et al. 2004; Caño et al. 2008; Qing et al. 2011; Moroney et al. 2013). Different trait means and different

84 reaction norms to the environmental gradient indicate a genetic shift in respectively the traits themselves and their

85 phenotypic plasticity (and indicate pre-adaptation otherwise). Such shifts can occur if genetic variation in trait

86 means or trait plasticity exists in the introduced populations and if this variation yields a fitness advantage in the

87 novel environment.

88 Some previous studies found evidence for pre-adaptation (e.g. DeWalt et al. 2004), while others support the genetic

89 shift hypothesis (e.g. Qing et al. 2011). However, different studies used different approaches. While all studies

90 compared trait means (e.g. Siemann and Rogers 2001; Hejda et al. 2009; Schlaepfer et al. 2010), fewer compared

91 also the phenotypic plasticity of traits between native and invasive populations, using either plasticity indices (e.g.

92 DeWalt et al. 2004) or the slope of the reaction norm to environmental treatments (e.g. Maron et al. 2004, Caño et

93 al. 2008, Qing et al. 2011, Moroney et al. 2013). Plasticity indices provide quick estimations but are weaker for

94 statistical comparison, whereas reaction norms are more reliable since they are the most direct way of exploring 
95 phenotypic plasticity (Valladares et al. 2006). Studies testing pre-adaptation vs. genetic shift on new species should

96 therefore use the best available methodology.

97 Here we investigate mechanisms underlying the invasion of a major invasive species in Europe, Impatiens

98 glandulifera. We determine whether high competitiveness, abundant reproduction and high phenotypic plasticity

99 were already present before invasion (pre-adaptation) or evolved after introduction (genetic shift) by comparing

100 offspring from the native and the invasive range. Importantly, we also test for the presence of genetic variation in

101 trait means and trait plasticity, which to our knowledge has not been done before in alien invasive species and could

102 shed more light on the causes for possible changes in phenotypic plasticity during the invasion process.

103

104

\section{MATERIALS AND METHODS}

$105 \quad 2.1$ Study species and populations

106 The Himalayan balsam, I. glandulifera Royle (Balsaminaceae), is a widespread, often riparian forb native to the

107 western Himalaya from Kashmir to Garhwal (India) (Hulme and Bremner 2006). After introduction in Great Britain

108 in 1839 it spread through Europe (Beerling and Perrins 1993), where it increased dramatically in abundance and

109 distribution during the past 30 to 40 years. The species is classified as one of the 100 most invasive species in

110 Europe (DAISIE 2008). It occurs in many different habitats, but thrives best under high nutrient and water

111 availability (Beerling and Perrins 1993; Pyšek and Prach 1995). I. glandulifera commonly reaches a height of up to

$1122.5 \mathrm{~m}$ and the plants in the invasive range are generally taller than in the native range (Beerling and Perrins 1993;

113 Pyšek and Prach 1995; Clements et al. 2008; Tanner et al. 2014). The species is annual, does not reproduce

114 vegetatively and has a limited seed bank; successful seed production and recruitment each year is therefore crucial

115 for maintenance and spread of populations (Skálová et al. 2012). Seeds are dispersed by ballistochory (Willis and

116 Hulme 2004), but long-distance dispersal often occurs by water currents, small rodents or man's deliberate or

117 inadvertent spread (Beerling and Perrins 1993).

Table 1: Location, average soil nitrogen availability measured with four PRS probes and average soil temperature

120 (measured with dataloggers) during six weeks of the growing season for the four study populations of Impatiens

121 glandulifera.

\begin{tabular}{lcccc}
\hline Population & Coordinates & $\begin{array}{c}\text { Altitude } \\
(\mathrm{m})\end{array}$ & $\begin{array}{c}\text { Nitrogen }(\mu \mathrm{g} \\
\mathrm{m}^{-2} \text { per } 6 \\
\text { weeks })\end{array}$ & $\begin{array}{c}\text { Soil } \\
\text { temperature } \\
\left({ }^{\circ} \mathrm{C}\right)\end{array}$ \\
\hline Invasive 1 (Malvik, Norway) & $63.413^{\circ} \mathrm{N} / 10.809^{\circ} \mathrm{E}$ & 35 & 65.3 & 12.8 \\
Invasive 2 (Stjørdal, Noway) & $63.484^{\circ} \mathrm{N} / 10.985^{\circ} \mathrm{E}$ & 170 & 12.2 & 12.5 \\
Native 1 (Gokhama, India) & $34.077^{\circ} \mathrm{N} / 74.488^{\circ} \mathrm{E}$ & 1850 & 7.7 & 21.6 \\
Native 2 (Paris Pora, India) & $34.087^{\circ} \mathrm{N} / 74.534^{\circ} \mathrm{E}$ & 1700 & 1.9 & 21.5 \\
\hline
\end{tabular}

122

123 The current study used the offspring from four populations of I. glandulifera (see Table 1 for population's

124 coordinates and characteristics), two from the native range (Kashmir, India) and two from the invasive range 
125 (Trondheim, Norway). The latter were chosen at the northern end of the invasive range in order to have maximal

126 differences in environmental conditions relative to the native range (Table 1). This maximizes the selective pressure

127 on the plants and thus the chance to detect any realized genetic shift (DeWalt et al. 2004; Maron et al. 2004;

128 Bossdrof et al. 2005; Caño et al. 2008; Qing et al. 2011; Colautti and Barrett 2013). Moreover, the Species Map

129 Service (Norwegian biodiversity information center and GBIF-Norway 2007-2014) indicates the presence of $I$.

130 glandulifera around Trondheim since 1949, which is considered sufficiently long for genetic shifts to be expressed

131 (Lee 2002).

132 During August and September 2011, mature seeds from a large number of capsules were collected from 30

133 randomly selected maternal plants in each population. After measuring their height, these plants were harvested and

134 oven dried for 72 hours at $60^{\circ} \mathrm{C}$ to determine the aboveground biomass. The average number of seeds per capsule

135 was obtained by dividing the total number of collected seeds by the number of collected capsules. The average seed

136 mass was obtained by dividing the mass of all collected seeds by the total number of seeds. In each population, four

137 PRS probes (Plant Root Simulator, Western Ag Innovations Inc., Saskatoon, Canada) were inserted vertically into

138 the soil at $5 \mathrm{~cm}$ depth to measure soil nitrogen availability during six weeks of the growing season (mid-June to end

139 of July 2011). These probes consist of an ion exchange resin membrane that is charged. When buried, soil ions

140 displace the counter-ions at a rate that depends on their diffusion rate in the soil. The quantity of soil ions absorbed

141 during a burial period is a function of all soil properties controlling nutrient availability in soil. After six weeks the

142 PRS probes were removed from the soil and the amount of nitrogen per surface area of membrane was measured.

143 Average soil nitrogen availability per population was calculated from the amount of nitrogen per surface area of

144 membrane measured on the four PRS probes in every population. During the same period, two data loggers (DS

145 1921G, NexSens Technology, Fondriest environment Inc., Beavercreek, Ohio, USA) per population measured the

146 top soil temperature at $2 \mathrm{~cm}$ depth every hour. All populations were located along roads and were assumed to have

147 experienced similar disturbance regimes.

\subsection{Experimental design}

150 Thirty seeds from each of 20 randomly selected maternal plants were kept dry at room temperature for two months 151 and then cold stratified at $4^{\circ} \mathrm{C}$ on moist filter paper in Petri dishes for three months. After germination, the seedlings 152 were cultivated in the glasshouse of the Department of Biology at NTNU (Trondheim, Norway). Mid-March 2012, 153 five developed seedlings were randomly selected from each maternal plant (family) and transplanted into one pot

154 (diameter $12 \mathrm{~cm}, 15 \mathrm{~cm}$ deep) filled with peat soil. Once the seedlings entered the true two-leaves stage, around 155 mid-April 2012, three of those five seedlings per maternal plant were transplanted individually into separate pots of 156 the same size, and each seedling was subjected to one of three different environments (see below). This represented 157240 individuals ( 2 ranges $\times 2$ populations $\times 20$ families $\times 3$ treatments).

158 The experiment was performed in three compartments of the glasshouse, where pots with offspring from the four 159 populations were randomly spread on a large tray filled with $5 \mathrm{~cm}$ of water. Environmental variation was generated

160 by temporarily replacing the water by a nutrient solution with a fixed concentration of nitrogen at different

161 frequencies, i.e. one day per week (High treatment), one day every two weeks (Intermediate treatment) or one day 
every three weeks (Low treatment). The added nutrients (YaraLiva ${ }^{\mathrm{TM}}$ CalciNit) contained $15.5 \%$ nitrogen and were supplied to achieve a concentration of $640 \mathrm{ppm}$ nitrogen in the nutrient solution. This nutrient solution was freely

164 available for the plants to take up during 24 hours, after which the trays were filled with $5 \mathrm{~cm}$ of water again the rest 165 of the time. There was no temperature control system in the different compartments; therefore differences in 166 temperature between the treatments cannot be excluded. Although this prevents us from assigning the effects to differences in nutrient availability only, we expect the nutrient gradient to be most influential. Moreover, possible other effects do not compromise the comparison of phenotypic plasticity between populations from the native and invasive range because all populations were exposed to the same environmental variation.

\subsection{Measurements}

172 In July and August 2012, when the plants were four to five months old and had been subjected to the nutrient 173 treatment for three months, we determined four reproductive and three vegetative traits on each offspring plant.

174 Reproductive traits included the number of flowers, the average number of seeds per capsule, the mean seed mass, 175 and the total reproductive output (see below). To estimate the average number of seeds per capsule, we performed 176 hand pollinations with randomly assigned donors and receivers within the same population, on several flowers per 177 plant (mean=25, $\min =2, \max =57$, depending on available flowers per plant). Hand pollination was carried out by 178 removing matured anthers from a flower of the pollen donor and applying the pollen to the receptive stigma of a 179 newly opened flower of the maternal individual. This was done after checking the stigma for any visible deposited 180 pollen and removing the corolla and nectar glands to prevent further pollination by insects visiting the rooms. To 181 prevent self-pollination, the anther from the pollinated flower was also detached (Nienhuis and Stout 2009). Hand 182 pollinated capsules that developed were covered with paper teabags and collected when most capsules had burst.

183 Seeds per capsule were counted and dried at room temperature for one year. All seeds collected per individual were 184 then weighted and the average seed mass was obtained by dividing the total mass by the total number of seeds. The 185 total number of flowers per plant was determined by counting the receptacles at the end of the growing season. A 186 proxy value for total reproductive output was calculated by multiplying the total number of flowers by the average 187 number of seeds per capsule and the percentage of pollinated capsules that formed seeds. The vegetative traits were 188 number of nodes, plant height and aboveground biomass. The number of nodes on the main stem was counted at 189 first flowering. Early August, plant height was measured from the base of the stem to the upper most photosynthetic 190 tissue, excluding the inflorescence. After these measurements were taken, the aboveground biomass was harvested 191 per individual, oven dried at $60^{\circ} \mathrm{C}$ for 72 hours and weighted to the nearest $0.1 \mathrm{~g}$.

\subsection{Statistical analyses}

194 Statistical analyses were done with R (R Development Core Team 2013). First we verified whether differences in 195 means between the populations in the field could be explained by the native $v s$. invasive range. This was done by 196 comparing models including population (four levels) or range (two levels) as the explanatory factor for every trait 197 measured in the field (plant height, dry aboveground biomass, number of seeds per capsule and seed mass). Models 198 were compared using a likelihood ratio test. A significant p-value indicates that the model with population (four 
levels) explains the trait variation better than the model with range (two levels). Note that only the field data from the 20 mother plants used in the experiment were included in the analysis of the field populations. To distinguish between genetic and environmental effects the offspring from these plants were grown in common garden in the glasshouse. Differences in reaction norms across populations in the glasshouse were tested with mixed-effects models where treatment and population were fixed factors and maternal family was a random factor (Appendix Table A 1). Treatments were categorized as -1, 0 and 1 for Low, Intermediate and High treatment, respectively, such that the intercept corresponded to the trait mean in the Intermediate treatment. As phenotypes were observed in three different environments, reaction norms could be non-linear. In environment $\mathrm{x}$, the individual phenotypic value $\mathrm{y}$ is given by $\mathrm{y}=\mathrm{A}+\mathrm{Bx}+\mathrm{cx}^{2}+\mathrm{E}$, where $\mathrm{A}, \mathrm{B}$ and $\mathrm{c}$ are the additive genotypic values for the intercept, the slope and the curvature of the reaction norm, respectively, and $\mathrm{E}$ is the environmental effect with a variance $\sigma_{\mathrm{E}}^{2}$. If a and $\mathrm{b}$ denote the population mean of $\mathrm{A}$ and $\mathrm{B}$, respectively, and assuming no genetic variance in $\mathrm{c}$, the observed phenotypes should be normally distributed with mean $\mathrm{E}(\mathrm{Y})=\mathrm{a}+\mathrm{bx}+\mathrm{cx}^{2}$ and a variance $\operatorname{var}(\mathrm{Y})=$ $\sigma_{\mathrm{A}}^{2}+\sigma_{\mathrm{B}}^{2} \mathrm{x}_{2}+2 \rho \sigma_{\mathrm{A}} \sigma_{\mathrm{B}} \mathrm{x}+\sigma_{\mathrm{E}}^{2}$, where the genetic variance and covariances of $\mathrm{A}$ and $\mathrm{B}$ are $\sigma_{\mathrm{A}}^{2}, \sigma_{\mathrm{B}}^{2}$, and $\rho \sigma_{\mathrm{A}} \sigma_{\mathrm{B}}$, respectively. In the mixed-effects models, the random (family) variance can be used to estimate the genetic variance in intercept (A) and slope (B). Indeed, considering two half-sibs in environments $\mathrm{x}_{1}$ and $\mathrm{x}_{2}$, their phenotype will be determined by the parental genotypic values as

and

$\mathrm{Y}_{2}=\frac{1}{2}\left(\mathrm{~A}_{\mathrm{m}}+\mathrm{A}_{\mathrm{f} 2}\right)+\epsilon_{\mathrm{A} 2}+\left[\frac{1}{2}\left(\mathrm{~B} \epsilon_{\mathrm{m}}+\mathrm{B}_{\mathrm{f} 2}\right)+\epsilon_{\mathrm{B} 2}\right] \mathrm{x}_{2}+\mathrm{cx}_{2}^{2}+\mathrm{E}_{2}$,

where $A_{m}, A_{f}, B_{m}$ and $B_{f}$ are the genotypic value for the intercept and the slope of the mother and father, and $\epsilon$ 's, representing Mendelian sampling and segregation, are normally distributed with zero means and variance $1 / 2 \sigma_{\mathrm{A}}^{2}$ and $1 / 2 \sigma_{\mathrm{B}}^{2}$ for the intercept and the slope, respectively. This can be fitted as a mixed effect regression model with random effect terms based on the mother identity on the intercept and slope, corresponding to the terms $1 / 2 \mathrm{~A}_{f i}$ and $1 / 2 \mathrm{~B}_{f i}$ in the above equations. From (1) and (2) it follows that, the variance of these random effect terms and their covariance can be seen to equal $1 / 4$ of the additive genetic variances in the reaction norm elevation and slope as well as $1 / 4$ of their covariance. Estimates of these variances are thus given by the estimated random effect variances multiplied by 4 . Because random variance in the slope $\sigma_{\mathrm{B}}^{2}$ was never observed, however, we did not have to consider the possible genetic covariance between the intercept and the slope. Assuming that the environmental variance equals the residual variance minus three times the family variance (because residual variance still contains the genetic variance due to the contribution of the male and Mendelian sampling variance equal to $\sigma_{\mathrm{A}}^{2} / 2$ ), heritability was estimated as: $\mathrm{h}^{2}=4 \times$ family variance / (residual variance + family variance). Note that if the different seeds from the same mother are sired by the same father, the estimate of the random variance will represent

232 In order to test the statistical significance of the random (family) variance we compared models fitted with restricted 233 maximum likelihood (REML) with different random effect (random effect for the slope and intercept vs. random 234 effect for the intercept only) using the likelihood ratio test. When statistically significant random variation in the 
slope or intercept was found, we further tested whether populations differed in their random variation by fitting the model anew for each population separately. The total log-likelihood for the model with variances differing between each population was then given by the sum of the log-likelihood of each separately fitted model. We used the change in log-likelihood between the two models which is Chi-square distributed $(\mathrm{df}=3)$ to test whether or not a model with different random variances was statistically better than a model with a single random variance common

240 for the four populations. We performed model selection, based on Akaike information criterion (AIC) values, for the 241 fixed effects using models fitted with maximum likelihood (ML). Parameter estimates were subsequently obtained

242 for the best model by refitting the model with REML. Finally, we tested for differences in phenotypic plasticity

243 between native and invasive populations by comparing the best model with a model where the factor population was

244 replaced by a factor range of origin (invasive vs. native).

245 Because we were interested in comparing relative differences among populations and traits, we performed all

246 analyses on log-transformed data. These models with log-transformed data had also a slightly better fit than the

247 models performed on raw data (not shown).

\section{$250 \quad 3.1$ Field measurements}

251 In the field, models including only populations were better than those including only range to explain differences in 252 plant height and dry aboveground biomass $(\mathrm{p}<0.001)$. Therefore, for these two traits, possible differences between 253 the native and invasive range were masked by the among-population differences within range. For the number of

254 seeds per capsule and the seed mass, on the other hand, differences between ranges were statistically significant and 255 larger than those among populations. Overall, plants in the invasive populations produced $62 \%$ less seeds per 256 capsule than those in the native populations, while their seeds were $43 \%$ heavier (Table 2).

258 Table 2: Mean \pm 1 se per population of Impatiens glandulifera for the four plant traits measured in the field.

259 I=Invasive, N=Native.

\begin{tabular}{lcccc}
\hline Population & $\begin{array}{c}\text { Number of } \\
\text { seeds per } \\
\text { capsule }\end{array}$ & Seed mass $(\mathrm{mg})$ & Plant height $(\mathrm{cm})$ & $\begin{array}{c}\text { Aboveground } \\
\text { biomass }(\mathrm{g})\end{array}$ \\
\hline $\mathrm{I} 1$ & $4.64 \pm 1.40$ & $10.25 \pm 0.56$ & $154.38 \pm 7.81$ & $8.96 \pm 1.05$ \\
$\mathrm{I} 2$ & $4.12 \pm 0.63$ & $10.92 \pm 0.46$ & $142.36 \pm 5.97$ & $9.07 \pm 1.00$ \\
$\mathrm{~N} 1$ & $11.67 \pm 0.72$ & $7.03 \pm 0.22$ & $109.20 \pm 5.82$ & $10.15 \pm 1.33$ \\
$\mathrm{~N} 2$ & $11.68 \pm 0.65$ & $7.80 \pm 0.26$ & $143.25 \pm 7.39$ & $27.29 \pm 3.70$ \\
\hline
\end{tabular}




\subsection{Glasshouse measurements}

262 In general, trait values increased from the Low to the High treatment, except for the average number of seeds per 263 capsule which was not affected (Fig. 1; Table 2 and 4). For the other traits, the increase from Intermediate to High 264 was generally stronger than the increase from Low to Intermediate, generating non-linear reaction norms (Fig. 1;

265 Table 3). In four out of the six traits affected by the treatment, neither the slope nor the curvature of the reaction 266 norm differed among populations or ranges (Table 3, Fig. 1). Hence, for these traits, phenotypic plasticity was 267 similar in native and invasive populations. For total reproductive output, the slope of the reaction norm differed 268 among the populations. One invasive population showed a modestly increasing reaction norm between the Low and 269 Intermediate treatment, while the other three populations showed a slight decrease (Fig. 1). For the number of nodes, 270 the curvature of the reaction norm was more pronounced in plants from the invasive range (Fig. 1; Table 3). This 271 indicates greater phenotypic plasticity for this trait in the invasive (33\% and 23\% increase from Low to High in 272 invasive population 1 and 2, respectively) than in the native populations (4\% and 6\% increase from Low to High in 273 native population 1 and 2 , respectively).

274 Plants originating from the invasive range produced less seeds per capsule and also had lower total reproductive 275 output than plants from the native range (Fig. 1, Table 2). For these two traits, the model with range of origin as 276 explanatory variable was better than the model with the separate populations. For the other traits, the best model was 277 the one including populations as explanatory variable, indicating that possible differences among ranges were 278 overshadowed by the among-population differences within range $(\mathrm{p}<0.001)$.

279 None of the traits showed statistically significant random variation in slope, and only one trait, the number of nodes, 280 showed significant random variation in the intercept (Table 3), suggesting that only this trait harbored genetic 281 variation. Furthermore, the amount of family variance for this trait differed among populations $\left(\chi^{2}=12.11, \mathrm{df}=3, \mathrm{p}\right.$

$282=0.007$ ) and was statistically significant only in one of the native populations, while it was marginally significant in 283 one native and one invasive population (Table 4). Heritability estimates for the number of nodes based on the 284 assumption that individuals from the same maternal plant were half-siblings, were particularly high for the three 285 populations harboring family variation ( 0.79 to 1.31 ). This suggests that most of the offspring from the same 286 maternal plant, grown in our glasshouse-experiment, were full-sibs (Table 4). 
Fig. 1: Mean \pm 1 se on log scale of the trait values of Impatiens glandulifera for each population in each treatment for (a) Number of flowers, (b) Number of seeds per capsule, (c) Seed mass, (d) Total reproductive output, (e) Plant height, (f) Aboveground biomass and (g) Number of nodes.
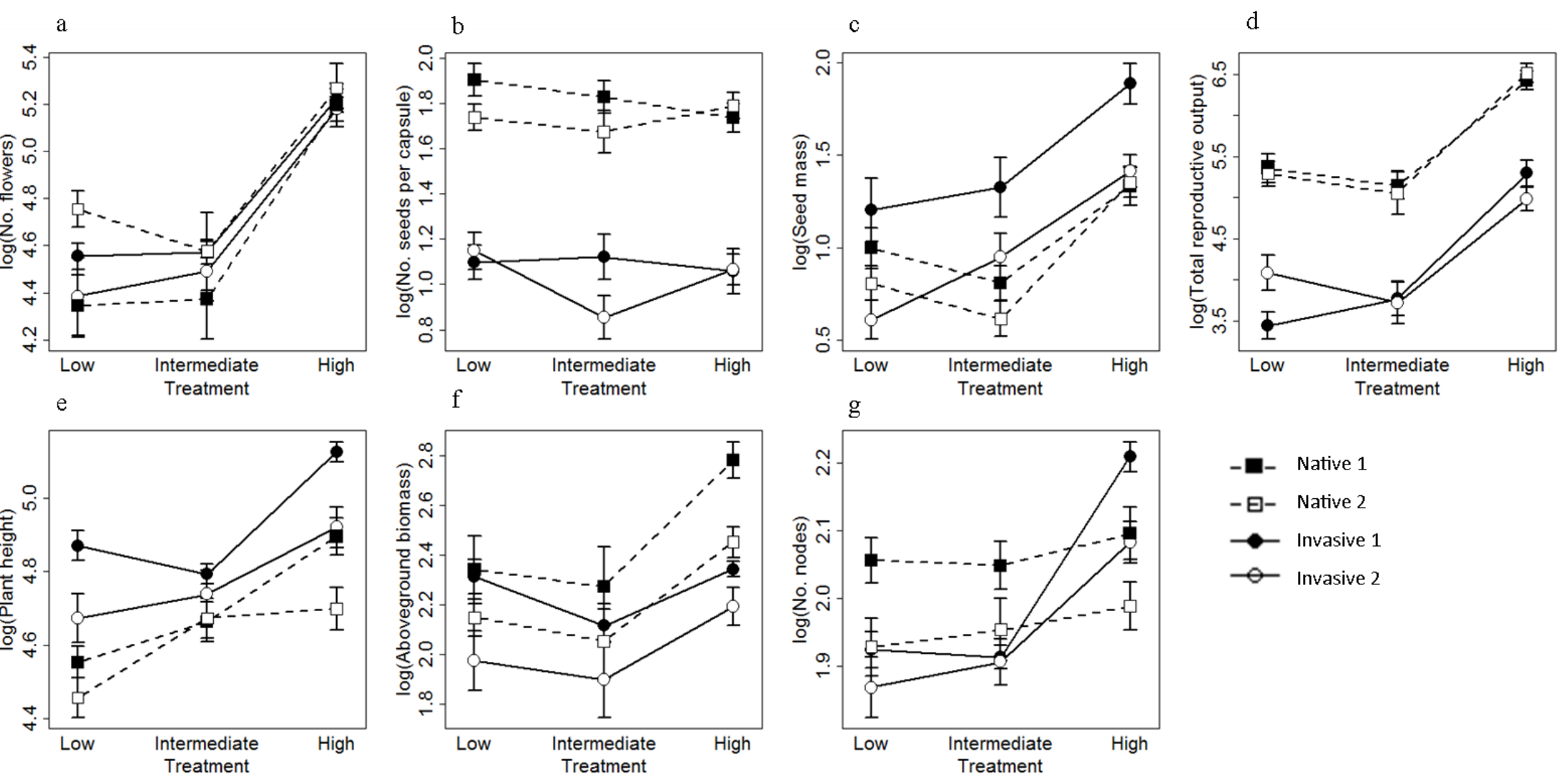

-[- Native 1

-曰- Native 2

- Invasive 1

Invasive 2 
291 Table 3: Parameter estimates \pm 1 se on log scale for the effects of treatment and population (I: invasive, $N$ : native) and statistical significance level of the random 292 effects for the slope and intercept on seven traits in Impatiens glandulifera in the glasshouse. Parameters were obtained from the best model fitted with REML

293 without global intercept. Consequently, the estimates for each population correspond to the mean value for each population in the Intermediate treatment. Models 294 included population and treatment as fixed factors and maternal family as a random factor. The p-values for the random variance in the intercept were calculated 295 using the exactRLRT function in R. Note: I=Invasive, N=Native.

296

\begin{tabular}{|c|c|c|c|c|c|c|c|}
\hline & $\begin{array}{c}\text { Number of } \\
\text { flowers }\end{array}$ & $\begin{array}{c}\text { Number of seeds } \\
\text { per capsule }\end{array}$ & $\begin{array}{l}\text { Seed mass } \\
(\mathrm{mg})\end{array}$ & $\begin{array}{l}\text { Reproductive } \\
\text { rate }\end{array}$ & $\begin{array}{l}\text { Plant height } \\
(\mathrm{cm})\end{array}$ & $\begin{array}{c}\text { Aboveground } \\
\text { biomass (g) }\end{array}$ & $\begin{array}{c}\text { Number of } \\
\text { nodes }\end{array}$ \\
\hline \multicolumn{8}{|l|}{ Fixed effects } \\
\hline Population I1 & $4.54 \pm 0.08$ & $1.09 \pm 0.05$ & $1.28 \pm 0.08$ & $3.67 \pm 0.13$ & $4.89 \pm 0.04$ & $2.10 \pm 0.07$ & $1.91 \pm 0.04$ \\
\hline Population I2 & $4.45 \pm 0.08$ & $1.03 \pm 0.05$ & $0.80 \pm 0.08$ & $3.76 \pm 0.13$ & $4.74 \pm 0.04$ & $1.86 \pm 0.07$ & $1.91 \pm 0.04$ \\
\hline Population N1 & $4.40 \pm 0.08$ & $1.82 \pm 0.05$ & $0.86 \pm 0.08$ & $5.15 \pm 0.13$ & $4.67 \pm 0.04$ & $2.31 \pm 0.07$ & $2.05 \pm 0.04$ \\
\hline Population N2 & $4.63 \pm 0.08$ & $1.73 \pm 0.05$ & $0.74 \pm 0.08$ & $5.12 \pm 0.13$ & $4.57 \pm 0.04$ & $2.06 \pm 0.07$ & $1.95 \pm 0.04$ \\
\hline Treatment & $0.35 \pm 0.04$ & & $0.30 \pm 0.04$ & & $0.14 \pm 0.02$ & $0.12 \pm 0.04$ & \\
\hline Treatment $^{2}$ & $0.36 \pm 0.07$ & & $0.28 \pm 0.07$ & $0.75 \pm 0.11$ & $0.05 \pm 0.03$ & $0.23 \pm 0.06$ & \\
\hline Treatment:Population I1 & & & & $0.93 \pm 0.13$ & & & $0.14 \pm 0.02$ \\
\hline Treatment:Population I2 & & & & $0.45 \pm 0.13$ & & & $0.11 \pm 0.02$ \\
\hline Treatment:Population N1 & & & & $0.53 \pm 0.13$ & & & $0.02 \pm 0.02$ \\
\hline Treatment:Population N2 & & & & $0.61 \pm 0.13$ & & & $0.03 \pm 0.02$ \\
\hline Population I1:Treatment ${ }^{2}$ & & & & & & & $0.15 \pm 0.04$ \\
\hline Population I2:Treatment ${ }^{2}$ & & & & & & & $0.07 \pm 0.04$ \\
\hline Population N1:Treatment ${ }^{2}$ & & & & & & & $0.03 \pm 0.04$ \\
\hline Population N2:Treatment ${ }^{2}$ & & & & & & & $0.00 \pm 0.04$ \\
\hline \multicolumn{8}{|l|}{ Random effects } \\
\hline Slope: Chisquare & 1.56 & 1.05 & $1.6 \mathrm{e}-08$ & 0.39 & 0 & $1.7 \mathrm{e}-08$ & 0.94 \\
\hline$d f$ & 2 & 2 & 2 & 2 & 2 & 2 & 2 \\
\hline$p$-value & 0.46 & 0.59 & 1 & 0.82 & 1 & 1 & 0.62 \\
\hline Intercept: $R L R T$ & 0 & 0 & 0 & 0 & 0 & 0 & 7.00 \\
\hline$p$-value & 0.49 & 0.49 & 1 & 1 & 0.49 & 1 & $<0.01$ \\
\hline
\end{tabular}


Table 4: Heritability $\left(\mathrm{h}^{2}\right)$ estimated for the number of nodes of Impatiens glandulifera from the different populations assuming that offspring were half- or full-sibs. The p-values and likelihood ratio test for the statistical significance

300 of the random variance in the intercept for each population are also reported.

\begin{tabular}{lccc}
\hline Population & $\mathrm{h}^{2}$ full sib & $\mathrm{h}^{2}$ half sib & $\mathrm{p}$-value random effect \\
\hline Invasive 1 & 0.00 & 0.00 & 0.477 (RLRT $=0.00)$ \\
Invasive 2 & 0.43 & 0.86 & 0.057 (RLRT $=2.39)$ \\
Native 1 & 0.39 & 0.79 & 0.072 (RLRT $=2.03)$ \\
Native 2 & 0.65 & 1.31 & 0.011 (RLRT $=5.48)$ \\
\hline
\end{tabular}

\section{DISCUSSION}

303 Overall we did not find evidence for invasive populations of I. glandulifera having greater vegetative growth, more 304 abundant reproductive output or higher phenotypic plasticity than native populations, suggesting that invasiveness 305 was not enhanced by changes in these traits after introduction.

306 The lack of differences in plant height and aboveground biomass between the native and invasive range in the field 307 as well as in the glasshouse contradicts the expectation of more vigorous growth in the new region as predicted by 308 the genetic shift hypothesis (Beerling and Perrins 1993; Pyšek and Prach 1995; DeWalt et al. 2004; Jakobs et al. 2004; Caño et al. 2008; Qing et al. 2011; Colautti and Barrett 2013; Moroney et al. 2013). Moreover, in the glasshouse, also the number of nodes and the total number of flowers produced per plant was similar in the offspring from both ranges. Consequently, these four traits were pre-adapted for invasion (Lee and Gelembiuk 2008; Mason et al. 2008; Hejda et al. 2009; Schlaepfer et al. 2010), at least if they effectively contribute to the species' invasiveness in the first place. Alternatively the lack of difference in plant height and aboveground biomass between the native and the invasive range could arise from the interaction between habitat productivity and herbivore defense (Zhang and Jiang, 2006). Coley et al. (1985) state that habitat productivity and defense against natural enemies may interact and as such shape the outcome of evolutionary changes in invasive plants (Zhang and Jiang, 2006). If species originate from a low productivity environment and invade a high productivity environment, as is the case for $I$. glandulifera, herbivore resistance can be reduced owing to re-allocation of resources from defense to growth (Zhang and Jiang, 2006). This may counteract the expected vigorous growth of the invasive species (Zhang and Jiang, 2006). Invasive populations of I. glandulifera produced less seeds per capsule than native populations, both in the field and in the glasshouse. This points to a genetic shift rather than pre-adaptation, probably induced by a genetic bottleneck after introduction (Kaufmann and Smouse 2001; DeWalt et al. 2004; Maron et al. 2004; Bossdorf et al. 2005; Caño et al. 2008; Qing et al. 2011; Colautti and Barrett 2013) and subsequent local adaptation to the low temperatures and short growing season in the invasive Norwegian populations (Kaufmann and Smouse 2001; Blair and Wolfe 2004; DeWalt et al. 2004; Maron et al. 2004; Bossdrof et al. 2005; Caño et al. 2008; Feng et al. 2008; Barney et al. 2009; Qing et al. 2011; Li et al. 2015). Plants in cold climates typically produce smaller amounts of seeds, though these seeds are generally larger than in warm regions (Landolt, 1967; Schütz \& Stöckin, 2001; Baskin \& Baskin, 2014). The latter may give rise to increased germination, better seedling survival, and greater vigour and competitive ability 
(Schmitt and Ehrhard 1990; Skálová et al. 2011, Willis and Hulme 2004). In the current experiment, we indeed also observed greater seed mass in the invasive than in the native populations, which had an environmental rather than a genetic origin because it was no longer present in the offspring in the glasshouse. Nutrients are known to be important for seed mass (Baskin \& Baskin, 2014), and seed mass in the glasshouse increased strongly when more nutrients were supplied. Moreover, in the field, we measured more available nutrients in the soil beneath the invasive populations than the native ones. Part of the invasiveness of this species may thus be generated by the production of larger seeds with higher seed quality under high nutrient conditions typical of the invasive range. In most of the traits we detected no difference in phenotypic plasticity between the ranges in the glasshouse. Therefore, we did not find evidence for an overall genetic shift in the plasticity of I. glandulifera in the invasive range. If phenotypic plasticity plays a role in the invasiveness of this species, then it may already be present at a similar level in the native populations, which is consistent with the pre-adaptation hypothesis (Lee and Gelembiuk 2008; Mason et al. 2008; Hejda et al. 2009; Schlaepfer et al. 2010). The additional random terms in the statistical model allowed us to ascertain whether differences in means and phenotypic plasticity could be explained by genetic variation (mean: intercept, phenotypic plasticity: slope). Sufficient additive genetic variation is essential for evolutionary adaptation to new environments (Lee 2002). The absence of genetic variation in the slope of the reaction norm suggests that the lack of change in phenotypic plasticity between native and invasive populations resulted from low genetic variation in phenotypic plasticity initially harbored by this species. One trait, the number of nodes, was more plastic in the invasive than in the native range (steeper slope and stronger curvature). However, for this trait as well, genetic variation in plasticity was absent, as only the mean value of this trait had genetic variation. Among the studies on other species that generally support the pre-adaptation hypothesis (e.g. DeWalt et al. 2004; Hejda et al. 2009; Schlaepfer et al. 2010), only DeWalt et al. (2004) studied phenotypic plasticity and they found no evidence for a shift in phenotypic plasticity of morphological and photosynthetic traits in Climedia hirta. On the other hand, studies lending support to the genetic shift hypothesis (e.g. Siemann and Rogers 2001; Maron et al. 2004; Caño et al. 2008; Qing et al. 2011; Colautti and Barrett 2013; Moroney et al. 2013) found increased phenotypic plasticity after introduction in Senecio pterophorus (Caño et al. 2008), Spartina alterniflora (Qing et al. 2011) and Centaurea melitensis (Moroney et al. 2013). The capacity to realize a genetic shift may thus be speciesspecific.

357 In conclusion, our study indicates that I. glandulifera is pre-adapted for invasion with respect to most of its traits, 358 both for their mean value and phenotypic plasticity. Only the number of nodes was more plastic in the invasive than 359 in the native range, pointing to a genetic shift in this trait. The number of seeds per capsule also showed a shift, but not toward more abundant reproduction as predicted by the genetic shift hypothesis. Invasive populations in the field did produce heavier seeds, probably owing to higher nutrient availability in the invasive range. From these findings we conclude that differences in habitat between ranges most likely drive the invasion of this species, as plants in the invasive range mainly occupy disturbed and nutrient rich sites. These conditions may therefore be the key determinant of the invasion process. 
368 This study was facilitated by the FLEUR-network funded by the Research Foundation-Flanders (FWO). We are

369 grateful to Nansenfondet for financial support to carry out the field work. We thank Sharmila Phuyal, Guri Hanssen,

370 Grete Rakvaag, Hélène Elst and Sigrid Lindmo for their help in the field and glasshouse and with processing

371 samples in the laboratory.

\section{LITERATURE CITED}

374 Barney JN, Whitlow TH, DiTommaso A (2009) Evolution of an invasive phenotype: shift to belowground

375 dominance and enhances competitive ability in the introduced range. Plant Ecol 202: 275-284.

376 Baskin CC, Baskin JM (2014) Seeds: Ecology, Biogeography and Evolution of Dormancy and Germination.

377 Elsevier.

378 Beerling D J, Perrins JM (1993) Impatiens glandulifera Royle (Impatiens-Roylei Walp). J Ecol 81: 367-382.

379 Blair AC, Wolfe LM (2004) The evolution of an invasive plant: an experimental study with Silene latifolia. Ecology 380 85: 3035-3042.

381 Bossdorf O, Auge H, Lafuma L, Rogers W, Siemann E, Prati D (2005) Phenotypic and genetic differentiation 382 between native and introduced plant populations. Oecologia 144: 1-11.

383 Caño L, Escarré J, Fleck I, Blanco-Moreno JM, and Sans FX (2008) Increased fitness and plasticity of an invasive 384 species in its introduced range: a study using Senecio pterophorus. J Ecol 96: 468-476.

385 Clements DR, Feenstra KR, Jones K, and Staniforth R (2008) The biology of invasive alien plants in Canada.

386 9. Impatiens glandulifera Royle. Can J Plant Sci 88:403-417.

387 Colautti RI, Barrett SCH (2013) Rapid Adaptation to climate facilitates range expansion of an invasive plant. 388 Science 342: 364-366.

389 Coley PD, Bryant JP, Chapin FS (1985) Resource availability and plant antiherbivore defense. Science 230: 895-899.

390 DAISIE European Invasive Alien Species Gateway (2008) 100 of the Worst. http://www.europe-

391 aliens.org/speciesTheWorst.do. Accessed 19th February 2014.

392 Davis MA, Grime JP, and Thompson K (2000) Fluctuating resources in plant communities: a general theory of 393 invasibility. J Ecol 88: 528-534.

394 DeWalt SJ, Denslow JS, Hamrick JL (2004) Biomass allocation, growth, and photosynthesis of genotypes from 395 native and introduced ranges of the tropical shrub Clidemia hirta. Oecologia 138: 521-531.

396 Feng Y, Lei Y, Wang R, Callaway RM, Valiente-Banuet A, Inderjit, Li Y, Zheng Y (2008) Evolutionary tradeoffs

397 for nitrogen allocation to photosynthesis versus cell walls in an invasive plant. P Natl Acad Sci USA 106: 18533981856. 

differ in their traits but not in their plasticity. Funct Ecol 25: 1248-1259.

401 Hayes KR, Barry SC (2008) Are there any consistent predictors of invasion success? Biol Invasions 10: 483-506.

402 Hejda M, Pyšek P, Pergl J, Sádlo J, Chytrý M, Jarošík V (2009) Invasion success of alien plants: do habitat affinities 403 in the native distribution range matter? Global Ecol Biogeogr 18: 372-382.

404 Hulme PE, Bremner ET (2006) Assessing the impact of Impatiens glandulifera on riparian habitats: partitioning 405 diversity components following species removal. J Appl Ecol 43: 43-50.

406 Jakobs G, Weber A, Edwards PJ (2004) Introduced plants of the invasive Solidago gigantea (Asteraceae) are larger 407 and grow denser than conspecifics in the native range. Divers Distrib 10: 11-19.

408 Kaufman SR, Smouse PE (2001) Comparing indigenous and introduced populations of Melaleuca quinquenervia 409 (Cav.) Blake: response of seedlings to water and pH levels. Oecologia 127: 487-494.

410 Lande R (2009) Adaptation to an extraordinary environment by evolution of phenotypic plasticity and genetic 411 assimilation. J Evol Biol 22: 1435-1446.

412 Landolt E (1967) Gebirgs- und Tieflandsippen von Blütenpflanzen im Bereich der Schweizer Alpen. Bot. Jb 86: $413 \quad 463-480$.

414 Lee C. E (2002) Evolutionary genetics of invasive species. Trends Ecol Evol 17: 386-391.

415 Lee CE, Gelembiuk GW (2008) Evolutionary origins of invasive populations. Evol Appl 1: 427-448.

416 Li XM, She DY, Zhang DY, Liao WJ (2015) Life history trait differentiation and local adaptation in invasive 417 populations of Ambrosia artemisiifolia in China. Oecologia 177: 669-677.

418 Maron JL, Vilà M, Bommarco R, Elmendorf S, Beardsley P (2004) Rapid evolution of an invasive plant. Ecol 419 Monogr 74: 261-280.

420 Mason RAB, Cooke J, Moles AT, Leishman MR (2008) Reproductive output of invasive versus native plants. 421 Global Ecol Biogeogr 17: 633-640.

422 Moroney JR, Rundel PW, Sork VL (2013) Phenotypic plasticity and differentiation in fitness-related traits in 423 invasive populations of the Mediterranean forb Centaurea Melitensis (Asteraceae). Am J Bot 100: 2040-2051.

424 Nienhuis CM, Stout JC (2009) Effectiveness of native bumblebees as pollinators of the alien invasive plant 425 Impatiens glandulifera (Balsaminaceae) in Ireland. JPE 1 (1): 1-11.

426 Norwegian Biodiversity Information Centre, GBIF-Norway (2007-2014) Species map service. 427 http://artskart.artsdatabanken.no/. Accessed 20 August 2014.

428 Prentis PJ, Wilson JRU, Dormontt EE, Richards DM, Lowe AJ (2008) Adaptive evolution in invasive species. 429 Trends Plant Sci: 13 (6): 288-294. 
Pyšek P, Prach K (1995) Invasion Dynamics of Impatiens glandulifera - a Century of Spreading Reconstructed. Biol Conserv 74: 41-48.

432 Qing H, Yao Y, Xiao Y, Hu F, Sun Y, Zhou C, An S (2011) Invasive and native tall forms of Spartina alterniflora 433 respond differently to nitrogen availability. Acta Oecol 37: 23-30.

434 R Core Team (2013). R: A language and environment for statistical computing. R Foundation for Statistical 435 Computing, Vienna, Austria. http://www.R-project.org/.

436 Richards CL, Bossdorf O, Muth NZ, Gurevitch J, Pigliucci M (2006) Jack of all trades, master of some? On the role 437 of phenotypic plasticity in plant invasions. Ecol Lett 9: 981-993.

438 Schlaepfer DR, Glättli M, Fischer M, van Kleunen M (2010) A multi-species experiment in their native range 439 indicates pre-adaptation of invasive alien plant species. New Phytol 185: 1087-1099.

440 Schütz W, Stöcklin J (2001) Seed weight differences between alpine and lowland plants. Verh GfÖ: 31-55.

441 Siemann E, Rogers WE (2001) Genetic differences in growth of an invasive tree species. Ecol Lett 4: 514-518.

442 Skálová H, Moravcová L, Pyšek P (2011) Germination dynamics and seedling frost resistance of invasive and native 443 Impatiens species reflect local climatic conditions. Perspect Plant Ecol 13: 173-180.

444 Skálová H, Havlíčková A, Pyšek P (2012) Seedling traits, plasticity and local differentiation as strategies of invasive 445 species of Impatiens in central Europe. Ann Bot 110: 1429-1438.

446 Schmitt J, Ehrhard DW (1990) Enhancement of inbreeding depression by dominance and suppression in Impatiens 447 capensis. Evolution 44: 269-278.

448 Tanner RA, Jin L, Shaw R, Murphy ST, Gange AC (2014) An ecological comparison of Impatiens glandulifera 449 Royle in the native and introduced range. Plant Ecol 215: 833-843.

450 Theoharides KA, Dukes JS (2007) Plant invasion across space and time: factors affecing nonindigenous species 451 success during four stages of invasion. New Phytol 176: 256-273.

452 Valladares F, Sanchez-Gomez D, Zavala MA (2006) Quantitative estimation of phenotypic plasticity: bridging the 453 gap between the evolutionary concept and its ecological applications. J Ecol 94: 1103-1116.

454 van Kleunen M, Weber E, Fischer M (2010) A meta-analysis of trait differences between invasive and non-invasive 455 plant species. Ecol Lett 13: 235-245.

456 Vitousek PM, D'Antonio CM, Loope LL, Westbrooks R (1996) Biological invasions and global environmental 457 change. Am Sci 84: 468-487.

458 Willis SG, Hulme PE (2004) Environmental severity and variation in the reproductive traits of Impatiens 459 glandulifera. Funct Ecol 18: 887-898.

460 Whitney KD, Gabler CA (2008) Rapid evolution in introduced species, 'invasive traits' and recipient communities: 461 challenges for predicting invasive potential. Divers Distrib 14: 569-580. 
462 Zhang DY, Jiang XH (2006) Interactive effects of habitat productivity and herbivore pressure on the evolution of 463 anti-herbivore defense in invasive plant populations. J Theor Biol 242: 935-940.

466 Table A 1: Model selection for the different traits of Impatiens glandulifera. Models A and B are used to compare if 467 the random effect for slope is significant. Models 1 to 8 are used to determine which fixed effects are needed in the 468 model. We first present the various models that have been fitted and then their AIC values per trait.

Model A $\log \mathrm{Y} \sim$ population+treatment:population+treatment ${ }^{2}+$ treatment $^{2}:$ population+(1|mother $)$

Model B $\quad \log \mathrm{Y} \sim$ population+treatment:population+treatment ${ }^{2}+$ treatment $^{2}:$ Population+(treatment|mother)

Model $1 \quad \log \mathrm{Y} \sim$ treatment+population+treatment:population+treatment ${ }^{2}+$ treatment $^{2}$ :population+(1|mother $)$

Model $2 \log \mathrm{Y} \sim$ treatment+population+treatment:population+treatment $^{2}+(1 \mid$ mother $)$

Model $3 \log \mathrm{Y} \sim$ treatment+population+treatment:population $+(1 \mid$ mother $)$

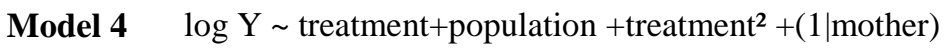

Model $5 \log \mathrm{Y} \sim$ treatment+population+(1|mother)

Model $6 \quad \log \mathrm{Y} \sim$ population+(1|mother)

Model $7 \quad \log \mathrm{Y} \sim$ treatment $+(1 \mid$ mother $)$

Model $8 \quad \log \mathrm{Y} \sim 1+(1 \mid$ mother $)$

\begin{tabular}{|c|c|c|c|c|c|c|}
\hline Trait & Model & $\mathrm{K}$ & $\mathrm{AICc}$ & $\triangle \mathrm{AiCc}$ & $\mathrm{AICcWt}$ & $\mathrm{AIC}$ \\
\hline \multirow{10}{*}{ Plant Height } & $\mathrm{A}$ & & & & & -11.1884 \\
\hline & $\mathrm{B}$ & & & & & -7.1884 \\
\hline & 1 & 14 & -9.32 & 0.2 & 0.35 & \\
\hline & 2 & 11 & -4.28 & 5.25 & 0.03 & \\
\hline & 3 & 10 & -3.16 & 6.37 & 0.02 & \\
\hline & 4 & 8 & -9.53 & 0 & 0.39 & \\
\hline & 5 & 7 & -8.37 & 1.16 & 0.22 & \\
\hline & 6 & 6 & 39.29 & 48.82 & 0 & \\
\hline & 7 & 4 & 31.47 & 10.99 & 0 & \\
\hline & 8 & 3 & 78.47 & 87.99 & 0 & \\
\hline \multirow[t]{10}{*}{ Aboveground biomass } & A & & & & & 333.14 \\
\hline & B & & & & & 337.14 \\
\hline & 1 & 14 & 335.02 & 8.67 & 0.01 & \\
\hline & 2 & 11 & 328.98 & 2.33 & 0.23 & \\
\hline & 3 & 10 & 339.88 & 13.54 & 0 & \\
\hline & 4 & 8 & 326.35 & & 0.75 & \\
\hline & 5 & 7 & 337.37 & 11.02 & 0 & \\
\hline & 6 & 6 & 345.96 & 19.62 & 0 & \\
\hline & 7 & 4 & 356.07 & 29.72 & 0 & \\
\hline & 8 & 3 & 363.46 & 37.12 & 0 & \\
\hline \multirow{5}{*}{ Number of nodes } & A & & & & & -201.79 \\
\hline & B & & & & & -198.73 \\
\hline & 1 & 14 & -199.92 & 0 & 0.73 & \\
\hline & 2 & 11 & -197.9 & 2.02 & 0.27 & \\
\hline & 3 & 10 & -189.64 & 10.29 & 0 & \\
\hline
\end{tabular}




\begin{tabular}{|c|c|c|c|c|c|c|}
\hline 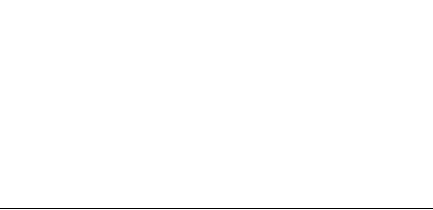 & $\begin{array}{l}4 \\
5 \\
6 \\
7 \\
8 \\
\end{array}$ & $\begin{array}{l}8 \\
7 \\
6 \\
4 \\
3 \\
\end{array}$ & $\begin{array}{l}-181.42 \\
-175.28 \\
-145.87 \\
-168.56 \\
-135.33 \\
\end{array}$ & $\begin{array}{l}18.5 \\
24.65 \\
54.06 \\
31.37 \\
64.59\end{array}$ & $\begin{array}{l}0 \\
0 \\
0 \\
0 \\
0\end{array}$ & \\
\hline Number of flowers & $\begin{array}{l}\mathrm{A} \\
\mathrm{B} \\
1 \\
2 \\
3 \\
4 \\
5 \\
6 \\
7 \\
8\end{array}$ & $\begin{array}{l}14 \\
11 \\
10 \\
8 \\
7 \\
6 \\
4 \\
3\end{array}$ & $\begin{array}{l}370.85 \\
364.9 \\
389.49 \\
361.12 \\
385.47 \\
446.77 \\
385.89 \\
445.7\end{array}$ & $\begin{array}{l}9.73 \\
3.78 \\
28.37 \\
0 \\
24.35 \\
85.65 \\
24.77 \\
84.58\end{array}$ & $\begin{array}{l}0.01 \\
0.13 \\
0 \\
0.86 \\
0 \\
0 \\
0 \\
0\end{array}$ & $\begin{array}{l}368.98 \\
371.42\end{array}$ \\
\hline $\begin{array}{l}\text { Average number of seeds per } \\
\text { capsule }\end{array}$ & $\begin{array}{l}\mathrm{A} \\
\mathrm{B} \\
1 \\
2 \\
3 \\
4 \\
5 \\
6 \\
7 \\
8\end{array}$ & $\begin{array}{l}14 \\
11 \\
10 \\
8 \\
7 \\
6 \\
4 \\
3\end{array}$ & $\begin{array}{l}191.42 \\
190.3 \\
190.26 \\
185.82 \\
185.77 \\
184.77 \\
286.01 \\
284.7\end{array}$ & $\begin{array}{l}6.65 \\
5.5 \\
5.49 \\
1.05 \\
1 \\
0 \\
101.24 \\
99.93\end{array}$ & $\begin{array}{l}0.02 \\
0.03 \\
0.03 \\
0.25 \\
0.26 \\
0.42 \\
0 \\
0\end{array}$ & $\begin{array}{l}189.50 \\
192.45\end{array}$ \\
\hline Average seed mass & $\begin{array}{l}\mathrm{A} \\
\mathrm{B} \\
1 \\
2 \\
3 \\
4 \\
5 \\
6 \\
7 \\
8\end{array}$ & $\begin{array}{l}14 \\
11 \\
10 \\
8 \\
7 \\
6 \\
4 \\
3\end{array}$ & $\begin{array}{l}361.14 \\
359.21 \\
372.85 \\
357.29 \\
370.44 \\
415.13 \\
401.72 \\
440.07\end{array}$ & $\begin{array}{l}3.85 \\
1.91 \\
15.56 \\
0 \\
13.15 \\
57.84 \\
4.43 \\
82.78\end{array}$ & $\begin{array}{l}0.1 \\
0.25 \\
0 \\
0.65 \\
0 \\
0 \\
0 \\
0\end{array}$ & $\begin{array}{l}359.22 \\
363.22\end{array}$ \\
\hline Total reproductive output & $\begin{array}{l}\mathrm{A} \\
\mathrm{B} \\
1 \\
2 \\
3 \\
4 \\
5 \\
6 \\
7 \\
8\end{array}$ & $\begin{array}{l}14 \\
11 \\
10 \\
8 \\
7 \\
6 \\
4 \\
3\end{array}$ & $\begin{array}{l}581.55 \\
575.56 \\
616.17 \\
577.25 \\
616.55 \\
685.13 \\
704.71 \\
764.86\end{array}$ & $\begin{array}{l}5.99 \\
0 \\
40.61 \\
1.68 \\
40.99 \\
109.57 \\
129.15 \\
189.3\end{array}$ & $\begin{array}{l}0.03 \\
0.68 \\
0 \\
0.29 \\
0 \\
0 \\
0 \\
0\end{array}$ & $\begin{array}{l}579.63 \\
583.25\end{array}$ \\
\hline
\end{tabular}

